\title{
CULTURA COMO OBJETO DE POLÍTICA PÚBLICA
}

\author{
José Carlos Durand \\ Sociólogo, Professor e Coordenador do Centro de Estudos da Cultura e do Consumo na FGV-SP
}

\begin{abstract}
Resumo: Apontam-se aqui alguns anacronismos, ambigüidades, indefinições e vazios da gestão cultural pública no Brasil, do nível local ao nacional. Seguem-se algumas sugestões corretivas inspiradas na sociologia, através de uma análise que também tenta aproveitar aspectos da experiência de países como Estados Unidos, França e Inglaterra.

Palavras-chave: política cultural; administração das artes; campo artístico.
\end{abstract}

É raro que qualquer debate sobre cultura, hoje, em países desenvolvidos, não vá desde logo explicitando duas circunstâncias fundamentais: o que é afinal relevante discutir; e quais são as qualificações necessárias - ou, ao menos, desejáveis - de quem se espera envolver nas discussões.

Tal consenso deriva da existência de uma pluralidade de interesses ativos na área cultural: grupos, associações, organismos, revistas, fontes de financiamento, identidades e qualificações intelectuais, técnicas, estéticas, políticas e administrativas, em um grau ainda difícil de se imaginar no Brasil e para as condições brasileiras. Tantos interesses e pontos de vista distintos se confrontam em espaços sociais relativamente independentes entre si. Trata-se de arenas cujos atores, em geral, conhecem seus interlocutores (efetivos e prováveis), de modo a não desperdiçar tempo e energia falando no deserto, ou, no extremo oposto, pregando a convertidos.

No que concerne ao amplo, diverso, rico e abstrato mundo da cultura, é lícito dizer que, naqueles países, há no mínimo 20 anos, uma linha divisória claramente se impõe entre "debater cultura" (sem mais qualificativos) e aquelas ocasiões em que cumpre entendê-la em função de um elenco delimitável e factível de alternativas de decisão política, econômica e administrativa. Muitos dos participantes de uma arena não têm interesse pela outra, e nela não costumam se envolver, o que aumenta, em con- seqüência, a produtividade da discussão em cada uma delas.

Não é o caso aqui, em hipótese alguma, de recusar importância à discussão dos múltiplos pontos de vista estéti$\cos$, teóricos ou ideológicos que fundamentam as controvérsias sobre cultura na imprensa, nos circuitos artísticos, na universidade, ou onde seja. Porém, cabe reconhecer que a abordagem da cultura como objeto de política e administração pública é, como se diz na gíria, um “outro departamento". Nele não pode ser admitida aquela tão comum postura individual de rejeição ético-ideológica do dinheiro e da economia, bem como a dificuldade daí derivada em entender que arte e cultura dependem de sustentação econômica e institucional como qualquer outra atividade humana. Ou seja, há muita gente (artistas, críticos de arte e acadêmicos da "área de humanas") que revela raro talento e vasto conhecimento ao navegar pelos meandros da arte e captar significados invisíveis ao olhar comum, mas que se infantiliza, emudece ou se torna agressiva quando o tema é política e gestão cultural. Isso ocorre porque essas pessoas partilham da visão idílica segundo a qual a presença da burocracia e do dinheiro na esfera cultural é por definição nefasta, independentemente de análise.

A intenção aqui é focalizar algumas questões que parecem constituir prioridades de política e gestão cultural para o Brasil, tal como surgem de uma visão panorâmica dessa área em países desenvolvidos ${ }^{1}$ e à luz da ainda es- 
parsa literatura brasileira, que avalia a experiência acumulada tanto em âmbito local, quanto de Estado ou de país (Durand, 2000). Como referência significativa, vale lembrar que o terreno da gestão cultural na França, Estados Unidos e Inglaterra está tão lavrado que há autores que chegam mesmo a definir "etapas" na breve história das políticas nacionais de cultura a partir do último pós-guerra (Volkerling, 1996; Bennet, 1995). ${ }^{2}$

\section{A FALTA DE VISÃO SISTÊMICA E DE COMPLEMENTARIDADE NA GESTÃO CULTURAL}

No Brasil, sequer se sabe quantas prefeituras possuem secretarias de cultura e, por conseguinte, em quantas os assuntos culturais são tratados através de secretarias de educação, esportes e turismo, ou outra qualquer. $\mathrm{O}$ fato de haver uma secretaria autônoma para cultura nos organogramas estadual e municipal não significa necessariamente que nos locais onde isso ocorre o trato da área seja mais eficiente, ágil e substantivamente melhor. Basta, a propósito, recordar o desgaste que foi, em âmbito federal, a criação do Ministério da Cultura no início do governo Sarney. Sem recursos e quadros técnicos que ao menos mantivessem a qualidade alcançada nas gestões imediatamente anteriores, tal "elevação" fragilizou tanto a área que foi fácil ao hostil governo Collor lançar a pá de cal, poucos anos depois (Botelho, 2001). Porém, tão escandalosa situação de desinformação não deixa de ser um sintoma de como ainda está atrasada a área na maior parte do país.

A par disso, é indispensável notar como é tênue e casuístico o relacionamento dos três níveis de governo nessa área, nos poucos casos em que algum intercâmbio existe. É muito freqüente as secretarias estaduais concentrarem recursos nas capitais dos Estados, sobrepondo-se às respectivas secretarias municipais, enquanto faltam visão e vontade sobre o que fazer no interior. O próprio Ministério da Cultura sustenta algumas fundações que - segundo se diz - ficariam melhor na alçada municipal e que se vinculam a ele pelo simples fato de se localizarem na cidade do Rio de Janeiro, que um dia foi sede do poder federal, e não serem reivindicadas por nenhuma outra instância.

Para se atingir um patamar mais consistente, será necessária uma visão mais orgânica e retrospectiva, capaz de avaliar e refletir sobre experiências prévias. Tal estágio será tanto mais distante e inatingível quanto mais as secretarias de cultura forem entregues a artistas e intelectuais consagrados que, na falta de um passado de admi- nistradores e de vontade política, tenderem a se comportar como "medalhões", julgando-se autorizados a orientar a ação de governo por linhas que sigam apenas suas preferências pessoais. Isso sem mencionar - pior ainda aqueles secretários que são escolhidos "à força" porque nenhum partido tenha se interessado por uma área tão pouco atrativa na partilha do orçamento e dos cargos politicamente compensadores. Esses dirigentes "de ocasião" com facilidade aspiram a marcar sua presença com projetos "de impacto", que, na maioria das vezes, consistem em "reinventar a roda".

Uma visão orgânica para a área cultural de governo também implica conhecer a divisão do trabalho que a lei e os costumes estabelecem entre governo e iniciativa privada em matéria de políticas sociais. Pode-se aqui apontar a pouca clareza que o meio artístico apresenta em relação ao que esteja ao alcance legal e político do governo, em cada nível administrativo, em matéria de regulação, financiamento direto, tutela e incentivos indiretos para a defesa e a promoção das artes e do patrimônio cultural. Nessa matéria, é indispensável distinguir aquilo que, em cada região ou localidade, está sendo suficientemente bem resolvido pela indústria cultural, ou por manifestações espontâneas da população, e aquilo que, com base em critérios defensáveis, o governo deve encorajar.

Ademais, cada gênero cultural tem seus "gargalos" próprios que só uma visão atenta e preocupada com interdependências pode detectar e superar. Exemplifique-se relembrando um caso singelo, mas bastante ilustrativo: a Funarte, nos anos 80, descobriu em dado momento que precisava ajudar fabricantes brasileiros a melhorar a qualidade de instrumentos musicais, visto ser tão precária que não tinha sentido continuar apoiando os grupos que os usavam sem nada propor a respeito (Botelho, 2001). Quantos casos mais de "gargalos" detectados e superados poderiam aqui merecer citação: certamente muito poucos, pois só acontecem raramente.

Uma visão sistêmica é necessariamente de longo prazo, embora seja possível "fazer explodir", do dia para a noite, o público de museus e concertos usando-se promoção intensiva na mídia de massa e/ou transformando uma exposição ou uma apresentação ao vivo em um "grande espetáculo". É isso que faz o marketing cultural quando uma verba polpuda o autoriza a ambicionar uma grande repercussão de mídia para a marca que patrocina um evento. Tanto é assim que se criou o neologismo "espetacularização", para dar conta da carga de "efeitos especiais" com que se reveste a manifestação artística, a fim de torná-la 
“acontecimento memorável". É sempre bom que se atraia o maior público possível, ao invés de deixar salas às moscas; todavia - como reiteradamente mostram as pesquisas -, a maior parte das pessoas levadas a um evento "espetacularizado" só voltará a eventos subseqüentes se atraída por igualmente custosa ${ }^{3}$ parafernália promocional. Para transformar um freqüentador ocasional em um apreciador regular de cultura, é preciso pensar a prazo mais longo. E dar-lhe educação artística.

A paisagem cultural só se enriquece e se diversifica consistentemente no longo prazo, fruto de processos de aprendizado e transmissão que alargam o repertório de gosto, a sensibilidade ao fazer artístico e o bolsão de amadorismo em que navega a maioria das pessoas que se sentem participantes desse pequeno universo. São esses processos que, em grande parte, dilatam socialmente as práticas amadoras, entendidas como o viveiro em que germinam e se consolidam as trajetórias que levam ao profissionalismo em artes e outras expressões culturais. ${ }^{4}$ Não é que não se faça nada para ampliar públicos para a cultura, no Brasil. Acontece que o pouco que se faz é desarticulado de uma visão mais abrangente, incapaz de dimensionar necessidades no tempo e no espaço e de articulá-las a diretrizes de política de educação, de cooperação internacional, de lazer e turismo, de fomento ao artesanato, de desenvolvimento regional, etc.

Nessa matéria, impossível aspirar a uma rapidez muito grande. A mudança e a diversificação do repertório estético, atreladas que estão à educação e ao estilo de vida e, secundariamente, ao nível econômico, acontecem devagar, pois os públicos para os gêneros contemplados diretamente pela área cultural governamental são minúsculos (entre menos de $1 \%$ e $10 \%$ da população total, variando conforme o gênero artístico). Assim, o mínimo que se pode fazer, além - é claro - de um reforço na educação estética, será montar pesquisas que retratem a "paisagem cultural" do lado da população, isto é, estudos metodologicamente consistentes, sensíveis o suficiente para captar traços de comportamento cultural até mesmo em grupos minúsculos e repetidos regularmente a cada década ou qüinqüênio. Em nenhum país desenvolvido a análise do desempenho da gestão cultural pública prescinde da "construção de paisagens" feita com rigor estatístico. ${ }^{5}$ Ainda no terreno do conhecimento quantitativo, é inaceitável que no Brasil os grandes conglomerados da indústria cultural monopolizem informações indispensáveis sobre o dimensionamento e as características do mercado, ao menos em áreas críticas como revistas e cinema.

\section{FONTES E MODOS DE FINANCIAMENTO DA CULTURA}

Entre as tendências já confirmadas nos últimos 20 anos, cresce o número de países que adotam um padrão "misto" de financiamento da cultura (Boorsma et alii, 1998), associando recursos públicos a "fundo perdido", a receitas geradas in loco - por exemplo, através da locação de espaço e da exploração de lojas, restaurantes, estacionamentos. Muito mais volumosos que os ganhos vindos de tais fontes, contudo, são os recursos de origem empresarial mobilizados na rubrica do "patrocínio corporativo". Seus objetivos, como todos sabem, é o ganho simbólico, ou de imagem, que a associação a um evento de prestígio pode oferecer a uma corporação e suas marcas.

A rotinização e a intensificação do patrocínio corporativo às artes, por sua vez, reclamam a profissionalização de intermediários e a descoberta de novas possibilidades de lucro econômico nos mercados culturais. Até aí tudo bem; mas essa nova fonte de recursos e a lógica de lucro que a anima põem séria questão: quais são os efeitos disso sobre o tipo de cultura que é oferecida, a quem e a que preço? Em suma, passa a ser necessário pensar o novo cenário distinguindo-se a dinâmica cultural e seus efeitos sociais $s o b$ os mencionados condicionamentos mercadológicos ou sem eles. A complicada tendência de a cultura erudita ser envolvida na lógica da indústria cultural é algo que merece análise cuidadosa. Vale muito a leitura de um estudo sensível de Olivier Donnat (1994) - sociólogo francês especializado em pesquisas quantitativas de hábitos e de comportamento cultural -, que mostrou a duvidosa, mas crescentemente importante, função de legitimação cultural que a mídia de massa vem assumindo.

É possível dizer que, do vértice de seus pesos numéricos, a cultura seja a área "número 1". Quando está robusta e saudável representa não mais de um por cento dos orçamentos públicos, da população economicamente ativa, do produto nacional bruto. Isso indica que um incremento significativo de sua receita de origem governamental não deve trazer sacrifícios dramáticos a outras áreas sociais com carências mais graves. No que tange ao patrocínio corporativo, o mais urgente a ser discutido é se os esforços da comunidade artística necessários para canalizá-los estão sendo recompensados com resultados, ou se ainda prevalece muita ilusão a respeito. Mais concretamente: se a trabalheira de encorajar centenas, milhares de artistas e produtores culturais a preparar projetos e muitas dezenas de técnicos de governo para recebê-los e avaliá-los esteja 
sendo correspondida por uma margem satisfatória de captação, ou se a maior parte desse esforço é mesmo "para inglês ver".

Por outro lado, sabe-se que a maior parte (cerca de dois terços) do dinheiro que circula na área cultural vem diretamente do bolso de quem frui (ou "consome") cultura, ao comprar livros, discos, ingressos de teatro e cinema, etc. Assim, pergunta-se: como é possível construir cenários da paisagem cultural sem levar em conta orçamentos familiares e os reflexos, em sua rubrica "lazer e cultura", das mudanças demográficas, educacionais, tecnológicas, de estilos de vida e de renda econômica?

Essas considerações sobre as bases materiais da vida artística leva à terceira indagação.

\section{A QUESTÃO DO "LADO FALTANTE"}

Essa expressão foi dita por um economista da assessoria de Celso Furtado, quando ministro da Cultura, no governo Sarney, em um seminário sobre políticas culturais. Segundo o assessor, que até aquele momento havia acompanhado Furtado em outros ministérios e agências, sempre que se tratava de avaliar a alocação de recursos para uma política pública, começava-se por caracterizar os grupos e interesses dos dois lados da produção de serviços a oferta e a demanda. A grande surpresa da assessoria, ao tentar extrapolar o mesmo e elementar raciocínio para a área cultural, foi verificar que nela parecia existir apenas um pólo - o da oferta. Isto quer dizer que as únicas manifestações de interesse - segundo aquele assessor - partiam dos grupos de artistas, produtores e dirigentes culturais à busca de recursos para seus projetos e instituições, nos balcões e gabinetes do MinC. Quanto à procura, o mais grave silêncio, indiferença, ignorância.

A reivindicação de uma atenção mais equilibrada a esses dois pólos não se apóia em nenhuma crença de que "sucesso de público" (ou grande audiência) seja indicador inequívoco de mérito artístico. Ademais, é coisa do passado supor que todo cidadão represente um "consumidor' de cultura, bastando ampliar a oferta que esta gerará automaticamente a procura.

Trata-se, simplesmente, de dimensionar e conhecer melhor os públicos de algum modo beneficiados com o gasto governamental, única maneira de tornar as decisões mais responsáveis, democraticamente. Tal exigência não se reduz em nada pelo fato de as atividades fomentadas pelo "braço cultural" governamental serem voltadas a uma parcela muito diminuta da sociedade. Em países onde o controle popular sobre o orçamento de governo se firma no princípio da "responsabilização" (accountability) como os Estados Unidos -, o financiamento de todo e qualquer programa ou projeto deve considerar suas conseqüências sobre a melhoria do acesso (access), entendida aí a ampliação de público, ou modificação em sua composição social para estratos menos favorecidos, ou melhoria de repertórios de gosto. Naquele país, tal cuidado não se aplica apenas a verbas de governo, mas também é critério cada vez mais crucial nas decisões das fundações e das corporações empresariais.

\section{A QUESTÃO DO “TABU DA QUALIDADE"}

A transformação das concepções a respeito da arte e da dinâmica do campo artístico, ao longo do século XX, acabou colocando sério embaraço para escolhas e decisões que precisam ser feitas pela gestão cultural pública. Em suma, se é um truísmo que ao governo não caiba produzir cultura nem decretar o valor dessa ou daquela obra ou movimento estético, nem desrespeitar a autonomia de criação e a pluralidade das culturas que coabitam em um mesmo país ou região, cabe perguntar: quais são as conseqüências disso sobre os limites e especificidades da ação estatal em termos de financiamento direto, de incentivos e de regulação na área cultural?

A melhor analogia aqui é com a política científica. Todos sabem que a comunidade acadêmica tem papelchave na definição de princípios de fomento, na criação de programas setoriais e na composição de colegiados para avaliar projetos, grupos de pesquisa, programas de pósgraduação, etc. Esse poder não caiu do céu, mas foi conquistado por uma luta sistemática, ao longo de décadas (Forjaz, 1988).

O controle acadêmico das verbas para pesquisa tem virtudes e defeitos que não cabe aqui serem discutidos. Basta que se assinale que este poder só pôde e continua podendo existir porque prevalece um consenso mínimo quanto ao que seja aceito como científico ou não. Esse consenso lastreia-se no reconhecimento de que o caráter científico está na partilha de um mesmo conjunto de procedimentos lógicos codificados - a metodologia científica. As avaliações ex ante ou ex post consistirão em apreciar se tais procedimentos vão ser ou foram obedecidos pelo pesquisador e se os resultados apresentam clareza e coerência. O nível da repercussão entre pares, nos canais competentes, subseqüentemente, distingüirá as iniciativas fecundas, que realmente fizeram avançar o conhecimen- 
to, daquelas mais modestas ou mesmo inócuas. Embora em anos recentes os órgãos de fomento à ciência estimulem investigações mais referidas a problemas práticos passíveis de serem enfrentados por ações de governo ou de empresas, a pesquisa puramente teórica, no extremo oposto, continua tendo seu espaço respeitado.

A analogia não visa insinuar que o fomento às artes possa ser administrado no mesmo feitio que o amparo à ciência. Falando das primeiras, um crítico francês, Philippe Urfalino, diz que "o governo não pode escolher, nem julgar, nem deixar isso aos pares" e, portanto, o melhor é "externalizar" as instâncias de julgamento, limitando-se o governo a financiar os projetos que comitês autônomos, escolhidos pela comunidade de pares e outros grupos, assim indicarem. Como, aliás, se faz na Inglaterra desde que Lorde Keynes criou o Arts Council, décadas atrás.

Por mais cômico que pareça, o problema está justamente aí. A comunidade artística, a rigor, não tem, nem pode mais ter, "representantes". As ideologias estéticas caminharam tanto na idéia de que a arte é inefável e que a graça do artista é soberana em definir o que pode ou não cair sob tal conceito, que aos críticos quase nada sobrou a não ser um trabalho subsidiário de comentadores. É uma postura tão comprometida com expectativas de brilho pessoal (e, às vezes, de ganho econômico) e com demandas de decifração quanto às obras, cujas qualidades a crítica em tese deveria assinalar e ajudar a serem compreendidas. Um exemplo eloqüente desse impasse mostrou-se quando, ao serem discutidos a natureza e os limites da avaliação de projetos a serem amparados pela lei de incentivo fiscal na cidade de São Paulo, concluiu-se que ela deveria apenas apreciar a compatibilidade entre o que o projeto propunha e a quantidade de tempo e dinheiro que seu autor solicitava para realizá-lo. Outra expressão desse impasse pode ser visto na nostalgia com que os críticos de arte de hoje referem-se a seus predecessores de meio século atrás, que se mostravam de público fortemente imbuídos de um sentimento de missão em discriminar o joio do trigo e seguros dos parâmetros estéticos e ideológicos que lhes permitiam dizer algo substantivo sobre as obras que analisavam (Durand, 1989 e 2001)

\section{DESCASO PARA COM AS INSTÂNCIAS DE CONSAGRAÇÃO}

As instâncias de consagração consistem num conjunto de indivíduos, grupos, eventos e instituições a quem se reconhece competência para avaliar e classificar obras, autores e movimentos estéticos. É claro que, no cotidiano, essa competência está sempre sendo questionada, pois a luta pela consagração - em que se embatem os artistas também envolve a luta pelo reconhecimento de autoridade e pelo acesso às posições de avaliação e classificação (Bourdieu, 1974).

Sempre coube, à área cultural governamental, abrigar e proteger os gêneros que compõem a cultura erudita, sobretudo aqueles que não conseguem sobreviver do mercado (Miceli e Gouveia, 1985). Embora a ênfase hoje em dia seja reconhecer como equivalente o valor tanto das expressões eruditas quanto das populares (multiculturalismo), isso em nada reduz a necessidade de a política cultural monitorar o avanço da indústria cultural, especialmente da estrangeira, sobre umas e outras. Monitoração aí não significa xenofobismo, bloqueio, patrulhamento ou censura, mas simplesmente o acompanhamento do alargamento do mercado e da globalização sobre a cultura nacional, no sentido de conhecer o saldo final de efeitos positivos e negativos, de modo a estabelecer o que pode ser feito para reforçar os primeiros e refrear os demais. Nessa tarefa, quanto mais a política cultural se apoiar no conhecimento pericial dos críticos para determinar qual é, afinal, esse saldo final de efeitos, tanto melhor será. Porém, para isso, será necessário pensar uma diretriz com relação àquelas instâncias, prestigiar sua constituição democrática e sua renovação e criar condições institucionais para que seu trabalho de avaliação e classificação seja divulgado regularmente, em uma linguagem suficientemente compreensível, à maior parcela possível dos que possam interessar-se em compreender as tendências de hibridação cultural ora em curso no Brasil e em qualquer outra parte do mundo.

Uma das fronteiras em que tal conhecimento pode produzir melhorias é a da diplomacia cultural. Entre as arengas que povoam a discussão de política cultural no Brasil, está a crítica ao pouco interesse que intelectuais e artistas brasileiros sempre teriam mostrado em relação aos demais países latino-americanos. Diz-se que se desconhecem mutuamente e que essa ignorância ajuda a alimentar uma perspectiva de admiração submissa que contribui para perpetuar a dependência cultural deste subcontinente em relação ao que se pensa e se cria nos pólos dominantes da Europa Ocidental e da América do Norte. Nessa vertente, uma ruptura, ou ao menos uma tentativa de confrontar essa desigualdade, passaria por um maior conhecimento e reconhecimento da qualidade das manifestações artísticas e culturais da América Latina e da localização de seus ele- 
mentos mais originais e profundos. Até aí, tudo bem. Pena é que fique só como declaração de intenções, como compromisso retórico, nas ocasiões em que tal encenação ainda consegue convencer. Porém, o que daí deriva de concreto é muito difícil de localizar. A diplomacia brasileira não se governa por diretrizes claras no domínio da cultura (Ribeiro, 1989), nem consegue administrar, com um mínimo de vontade efetiva e continuidade, as frentes de colaboração cultural que poderiam produzir uma tênue reversão que seja no quadro anteriormente desenhado. $\mathrm{O}$ exemplo mais desanimador está no fechamento, por restrição orçamentária, de várias das Casas de Cultura Brasileira que o Itamaraty havia aberto em países vizinhos, na tentativa de difundir a língua portuguesa e a cultura nacional. Também não se detecta, nem no MRE nem no MinC, nenhum programa (quando menos uma diretriz efetiva) para ajudar o artista brasileiro a devotar mais atenção a países vizinhos, nem para conceder meios materiais para artistas de países vizinhos vivenciarem a realidade sociocultural brasileira. Isso poderia ser feito dando-lhes condições de viajar e trabalhar mais dentro do continente, de enfrentar confrontos de seu trabalho no circuito regional, antes de migrar temporária ou definitivamente para algum centro de Primeiro Mundo.

Com a expansão rápida do número de artistas em face da conjugação de vários fatores (avanços na escolarização, em geral, e nas artes, em particular, barateamento das viagens e dos bens culturais em suporte industrial, tais como discos, fitas, livros, etc.), vem crescendo bastante o bolsão de amadorismo artístico nas grandes cidades. Por sua vez, a mercantilização crescente do campo artístico via corporate sponsorship tem favorecido a proliferação de premiações (festivais, prêmios literários, antologias, etc. $)^{6}$ por parte de empresas e institutos culturais a elas ligados (Durand, 1999).

Correlata ao adensamento das competições, ocorre a perda progressiva do poder de consagração de muitas delas. Pior, cada vez menos se aproveita de tais momentos para um balanço mais efetivo dos rumos que norteiam o universo artístico e dos "gargalos" que possam estar deprimindo sua expansão e qualidade. Aceitando-se que a gestão cultural pública tenha, junto aos círculos de cultura erudita, mais legitimidade que bancos e indústrias para criar e administrar premiações significativas, cabe despertar para o potencial que se abre nessa frente. Ou seja, sabendo usar seu poder de chancela e de mobilização da comunidade artística através de premiações, as secretarias de cultura têm aí um po- tencial de influência positiva ainda inexplorado: contribuir para uma explicitação minimamente consistente da idéia de qualidade no universo da estética, criando situações que forcem a crítica de arte a uma atuação menos enrustida e irresponsável, além de ajudar a traçar nexos de dependência simbólica entre países e regiões, pois as premiações constituem um momento por excelência para "fazer o balanço" do intercâmbio de influências culturais entre seus artistas (Durand, 2001).

\section{CONSIDERAÇÕES FINAIS}

O que é possível e desejável que o Estado faça na área cultural, nos dias que correm? Esta pergunta não tem resposta fácil sobretudo por duas razões.

A primeira é que a autoridade pública em cultura tem de operar com um espaço da sociedade que é internamente subdividido em subespaços governados por lógicas diferentes - a cultura erudita, a indústria cultural e as culturas populares. Em cada um desses três espaços a autoridade pública deve manifestar ou uma linha clara de ação ou, ao menos, uma justificativa consistente sobre o que pode ser feito como financiamento direto, fomento indireto ou regulação. Ou ainda, ao contrário, o que merece ficar como está, existindo espontaneamente sem necessidade de estímulo, ajuda ou intervenção. O Brasil é uma nação de grandes dimensões de território e população com significativa diversidade étnica e regional. Ademais, comporta uma sólida indústria cultural e um sistema de ensino capaz de dinamizar mudanças de gosto, estilos de vida e lazer. Tudo isso reclama a necessidade de uma visão mais orgânica que entenda gestão cultural como algo mais do que simplesmente promover eventos e restaurar sítios históricos, como até agora, quase sempre e na melhor das hipóteses, se faz. ${ }^{7}$

Em segundo lugar, faz parte das tendências de época o apelo às artes e à cultura para ajudar na busca de soluções de problemas que lhe são alheios. Aí entram a criação de empregos, o estímulo ao turismo, a reciclagem de áreas urbanas deterioradas, a recuperação de infratores, a cura mental, a reconciliação entre raças e entre religiões, a contenção da violência ${ }^{8}$ a integração de segmentos economicamente marginalizados, a facilitação do aprendizado e vários outros (Yúdice, 1997). Não cabe aqui discutir o tamanho, as características e o mérito de cada uma dessas novas demandas; ao contrário, o fundamental é reconhecer que, se os gestores públicos não forem capazes sequer de pensar 
orgânica e integradamente a área cultural em suas dinâmicas internas (no plural) e em suas interdependências, muito menos estarão preparados para entender a contribuição que podem e devem dar a necessidades mais agudas e que dependem de diagnósticos mais sofisticados e da interlocução com áreas de política pública, em que, geralmente, se sabe melhor o que fazer.

\section{NOTAS}

E-mail do autor: durand@fgvsp.br

Agradecimentos ao Núcleo de Pesquisas e Publicações da EAESP/FGV pelo auxílio no custeio da pesquisa que está na origem desta análise.

1. Tal visão foi propiciada pela participação do autor em uma estadia pós-doutoral em Nova York, no convívio com sociólogos da cultura, economistas, gestores de instituições culturais e professores de Arts Administration, em 1999 e 2000.

2. O neozelandês Michael Volkerling distingue uma fase inicial, de 1945 a 1965 , em que a orientação central era difundir a cultura erudita ao conjunto da população, seguida de dois decênios (1965-1985) em que a palavra de ordem passou a ser "multiculturalismo", admitindo-se que o governo deveria contemplar com atenção e fomento a expressão cultural de todas as classes, grupos e etnias dentro de uma dada sociedade nacional. A terceira fase, a partir de 1985 , seria marcada pela privatização de instituições culturais, pelo patrocínio corporativo e pela emergência de eventos globalizados.

3. O custo da "espetacularização" encarece muitas vezes o evento cultural, alijando boa parcela dos aficcionados que o freqüentavam pagando de seu bolso. Uma montagem de ópera no Rio de Janeiro, com artistas estrangeiros, custava em torno de 100.000 dólares até os anos 60, passando a 3 milhões de dólares a partir da década seguinte, segundo texto publicado pelo MinC (Weffort e Souza, 1998:212/214)

4. A "auréola" de amadorismo e semi-amadorismo que envolve o núcleo profissionalizado das artes recobre, grosso modo, de $80 \%$ a $90 \%$ das pessoas aí situadas pelas pesquisas demográficas e socioocupacionais feitas naqueles três países mencionados.

5. Por exemplo, a população americana despende semanalmente cerca de 17 horas semanais diante da TV e apenas cinco minutos com as artes eruditas (museus, concertos, dança, etc.) (Robinson e Godbey, 1997). A despeito disso, nos últimos 40 anos são feitas pesquisas periódicas para ver como esses públicos diminutos têm variado e que implicações isso traz para a avaliação de políticas culturais passadas e construção de cenários futuros (ver contribuições reunidas em Bradford et alii, 2000).

6. Sirva de constatação o fato de que na Inglaterra, entre 1988 e 1998, os prêmios literários aumentaram de 180 para 250, segundo mostra Marie Françoise Cachin (1998)

7. Era freqüente, em debates, palestras e reportagens, Rodolfo Konder, titular da Secretaria Municipal de Cultural de São Paulo nas gestões de Paulo Maluf e Celso Pitta, procurar "provar" o desempenho de sua gestão com uma certa "estatística mensal de eventos realizados", sem cuidado em revelar ao público como tais números eram recolhidos e o que de fato significavam. Lembre-se que se trata de um dos três maiores orçamentos para cultura em todo o país

8. A imprensa paulista noticiou recentemente a implantação de programas culturais no Jardim Ângela, bairro da periferia sul da cidade de São Paulo, com o objetivo de contribuir para neutralizar o poder do tráfico de drogas e reduzir um índice de violência excepcionalmente alto. Isso mostra que a gestão cultural tem um potencial de efeitos positivos para dimensões da vida social, em que a gravidade dos problemas é infinitamente maior.

\section{REFERÊNCIAS BIBLIOGRÁFICAS}

BENNETT, O. "Cultural policy in the United Kingdom: collapsing rationales and the end of a tradition". Cultural Policy, v.1, n.2, 1995, p.199-216.

BOORSMA, P.B. et alii (orgs.). Privatization and culture. Experiences in the arts, heritage and cultural industries in Europe. Boston, Kluwer, 1998.

BOTELHO, I. Romance de formação. A Funarte e a política cultural-1976/ 1990. Rio de Janeiro, MinC/Ed.Casa de Ruy Barbosa, 2001.

BOURDIEU, P. "O mercado de bens simbólicos". A economia das trocas simbólicas. São Paulo, Perspectiva, 1974, p.99-182.

BRADFORD, G. et alii (orgs.). The politics of culture. Policy perspectives for individuals, institutions, and communities. Nova York, The New York Press, 2000.

CACHIN, M.F. "La course aux prix en Grande-Bretagne". Liber. Revue Internationale des Livres, n.34, maio 1998, p.8-9.

DONNAT, O. "Mídia e publicidade: novos espaços de consagração cultural". In: . Les Français face à la culture. Paris, La Découverte, 1994, p.14050 (Tradução José Carlos Durand. Caderno do Centro de Estudos da Cultura e do Consumo).

. "La stratification sociale des pratiques culturelles et son évolution 1973-1997”. Revue Française de Sociologie, XL-1, 1999, p.111-19.

DURAND, J.C. Arte, privilégio e distinção. Artes Plásticas, Arquitetura e Classe Dirigente no Brasil, 1855/1985. São Paulo, Perspectiva, 1989 (col. Estudos, n.108).

"Awards as cultural policy instruments. A proposal for Latin America". International Conference on Cultural Policy Research. Anais.. Bergen, Noruega, v.1, nov. 1999, p.244-54.

Política e gestão cultural: Brasil, EUA, Europa. São Paulo, Núcleo de Pesquisas e Publicações da EAESP/FGV. Relatório de Pesquisa n.13, 2000.

Crítica de arte: cômoda irresponsabilidade e missão não cumprida. São Paulo, 2001, mimeo.

FORJAZ, M.C. Cientistas e militares no desenvolvimento do CNPq (1950-1985). São Paulo, Idesp/Série História das Ciências Sociais, n.4, 1988.

MICELI, S. e GOUVEIA, M. Politica cultural comparada. Rio de Janeiro/São Paulo, Funarte/Idesp, 1985.

RIBEIRO, E.T. Diplomacia cultural. Seu papel na política externa brasileira. Brasília, Fundação Alexandre de Gusmão/Instituto de Pesquisa de Relações Internacionais, 1989.

ROBINSON, J.P. e GODBEY, G. Time for life. The surprising ways americans use their time. Pennsylvania, University Park, 1997.

URFALINO, P. "Les politiques culturelles: mécénat caché et académies invisibles". L'Année Sociologique, 39, 1989, p.81-109.

VOLKERLING, M. "Desconstructing the difference-engine: a theory of cultural policy". Cultural Policy, v.2, n.2, 1996, p.189-212.

WEFFORT, F. e SOUZA, M. Um olhar sobre a cultura brasileira. Rio de Janeiro, Funarte, 1998.

YÚDICE, G. "The privatization of culture". Texto disponível no site da Universidade de Nova York (www.nyu.edu) na página do "The Privatization of Culture Project for Research on Cultural Policy”, 1997. 